\title{
INDICATIONS OF PRIMARY CAESAREAN SECTIONS AMONG IRAQI WOMEN IN KARBALA CITY DURING 2018
}

\author{
EMAN MAHDI MOHAMMAD ${ }^{1 *}$, SAAD IBRAHIM AL-GHABBAN ${ }^{2}$, MOUSA MOHSIN AL-ALAK ${ }^{2}$ \\ ${ }^{1}$ Karbala Health Directorate/Primary Health Centers, Karbala, Iraq, ${ }^{2}$ Kerbala University/Collage of medicine, Karbala, Iraq \\ Email: d824717@gmail.com
}

Received: 12 Aug 2019, Revised and Accepted: 15 Oct 2019

\section{ABSTRACT}

Objective: To study the different indications of primary caesarean sections for women attending Karbala Maternity Teaching Hospital and Al-kafeel Super Specialty hospital.

Methods: This was cross-sectional study, the sample was 330 women. Over the period from ${ }^{1 s t}$ January 2018 to [30] ${ }^{\text {th }}$ June 2018 . Questionnaire was filled by direct interviews. A pilot study was done; the subjects of the pilot including 20 women with previous PCS, and some modifications were occurred done accordingly. The sample of study was convenient sample including all women for whom PCS was done in the first time, it was 330 women. Then data was entered and analyzed by SPSS program version 22.

Results: The commonest age group in this study was (25-29) year, which represent $32.1 \%$. Majority of the study sample (49.7\%) were primigravida. The percentage of indications of Caesarean section include fetal distress $22.1 \%$, prolonged labor $18.5 \%$, malpresentation $17.3 \%$ and amniotic fluid leakage $16.4 \%$. Emergency CS had $43.6 \%$, and maternal request had $21.5 \%$.

Conclusion: Largest number of participant were primigravidarum which read big and serious problem for women life in future. Most women had taken regular antenatal care. Fetal distress and prolonged labor were the most common indications for caesarean section. Fetal outcome was good that reflect good antenatal care and perinatal care.

Keywords: Caesarean section, Primary caesarean section, Indications

(C) 2019 The Authors. Published by Innovare Academic Sciences Pvt Ltd. This is an open access article under the CC BY license (http://creativecommons.org/licenses/by/4.0/)

DOI: http://dx.doi.org/10.22159/ijcpr.2019v11i6.36360

\section{INTRODUCTION}

Caesarean section was called Primary Cesarean section (PCS) when it is performed for the first time on a pregnant woman $[1,2]$.

Since the 1970s, the primary cesarean section witness global rising especially in developed countries. In Iraq CS rate was $33.1 \%$ according to last annual statistical report of ministry of health at 2016. Hence, this study is important $[1,3,13]$.

However, this spreading of rising CS rates has not been limited to developed countries alone; developing countries also is consider epidemic with this increasing [4].

In 1985, new declaration was produced by World Health Organization (WHO); (no justification for any region to have a caesarean section rate higher than 10-15\%). This declaration was up on the evidence present at this period and on the CS rates detected in northern European countries, because it among the lowest maternal and perinatal mortality worldwide. After that, the international community put this representation as the "optimal" CS rate due to rising the rates of CS in both developed and developing countries [5, 6].

In general, an improvement in maternal surgical outcomes and progress in obstetric practice were claimed to be an arising in performance of caesarean section $[7,8]$.

Also safety modern an aesthesia, blood transfusion, antibiotics and the technical development of surgery and the advanced devices in the field of obstetrics and gynecology and neonatology units. All the above have led to the expansion of the Caesarean section. Beside that there have been other obstetrics, medical, social, ethical, economic and medico legal factors which have added to the list of indications leading to alarmingly high rate of caesarean sections all over the world [1,4].

Increasing the indications for caesarean section are usually relative rather than absolute, and include all those conditions in which the risk of vaginal delivery is assumed greater for mother or fetus than the risk of operation [1].
The most common clinical indications associated with higher primary cesarean rate are labor arrest disorders (dystocia), fetal distress, suspected macrosomia (defined alternatively as estimated fetal weight 4000 or $4500 \mathrm{~g}$ ), malpresentation, and multiple pregnancy. Common clinical parameters associated with the modern-day primary cesarean rate include failure induction of labor, maternal overweight-obesity, umbilical cord deformity, advanced maternal age, and women's request for cesarean may be due for tubal ligation or due to previous bad obstetrical history $[9,10]$.

Skill and experience of the surgeon and the quality of care from supporting staff especially those in anesthesia play important role in increase or decrease of mortality and morbidity after the Caesarean section.

The rate of cesarean delivery is often assessed the hospitals and health systems, the low percentage reflects more suitable, more efficient clinical practice and conserve optimal level of CS [11].

Primary cesarean delivery will become one of the important determinants of cesarean rate in recent years, Due to large numbers of women trying vaginal birth after cesarean had drop [12].

\section{MATERIALS AND METHODS}

It was a cross-sectional study carried out in kerbala Maternity Teaching Hospital and Al-kafeel Super Specialty Hospital in Holy Karbala over the period from $1^{\text {st }}$ January 2018 to $30^{\text {th }}$ June 2018.

A questionnaire form was designed in light of the reference to previous studies taking in consideration some suggestions and validated by panel experts. It includes socio-demographic data, the past medical history, Gestational history, past obstetrical history, Obstetrical history, gestational age, antenatal care.

The indication for caesarean section, the type of surgery done and fetal outcome was also reported. 
Data regarding indications of PCS which are related to mother including chronic diseases, Cephalo-pelvic disproportion (contraction or subluxation of the pelvic bones of mother), placenta problems (Previa, abruption, accrete), failure of induction of labor, sexually transmitted diseases, previous uterine rupture, tubal ligation and maternal age were all reported.

Data regarding the indication of PCS which are related to fetus including malpresentation (abnormal fetal in uterus position), suspected macrosomia (Fetal macrosomia, often defined as an estimated weight (4500 g), leakage of amniotic fluid, umbilical cord anomaly, fetal distress, twin or multiple pregnancy, high risky previous baby were all reported.

Data regarding the causes of PCS which are related to labor time including sever uterine bleeding, sudden increase of blood pressure, prolonged labor or failure to progress (dystocia), fit and uterine rupture were all reported.

A pilot study was done; the subjects of the pilot, including 20 women with previous PCS, and some modifications done accordingly.

The sample of the study was convenient sample including all women for whom PCS was done in the first time, it was 330 women.

Then data was entered and analyzed by SPSS program version 22 .

\section{RESULTS}

There were 330 women enrolled in this study. The mean age of the women was $(26.33 \pm 6.206)$ years and the range was $30 \mathrm{y}$; furthermore, age was categorized into six age groups. Also, address and educational levels in table 1 .

Table 1: Shows the distribution of women according to age

\begin{tabular}{lll}
\hline Variables & Frequency & Percent \\
\hline Age group & & 13 \\
less than 20 & 43 & 29.1 \\
$24-20$ & 96 & 32.1 \\
$29-25$ & 106 & 11.5 \\
$34-30$ & 38 & 11.2 \\
$39-35$ & 37 & 3 \\
40 and more & 10 & 76.1 \\
Address & & 23.9 \\
Urban & 251 & 7.0 \\
Rural & 79 & 24.2 \\
Educational Level & & 34.2 \\
Uneducated & 23 & 33.9 \\
Srimary School & 80 & 0.6 \\
Institute Or College & 113 & 112 \\
Other & 2 & \\
\hline
\end{tabular}

Fetal distress was topped the list of indications of primary caesarean section $22.1 \%$, prolonged labor was the second indications in our study $18.5 \%$, malpresentation had $17.3 \%$, Amniotic fluid leakage had 16.4 and Cephalo-pelvic disproportion had 14.2\%. And other indications included Chronic disease of the mother, Failed induction of labor, Previous high-risk baby, bleeding during labor, macrosomia, tubal ligation,

Umbilical cord deformity, maternal fit, sudden hypertension, multiple pregnancy and previous uterine rupture as present in table 2 .

Table 2: Shows the distribution of women according to indications for caesarean section

\begin{tabular}{lll}
\hline Indications & Frequency & Percent \\
\hline Fetal distress & 73 & 22.1 \\
Prolonged labor & 61 & 57 \\
Malpresentation & 54 & 17.5 \\
Amniotic fluid leakage & 47 & 16.4 \\
Cephalo-pelvic disproportion & 39 & 14.2 \\
Chronic disease of the mother & 38 & 11.8 \\
Failed induction of labor & 25 & 11.5 \\
Previous high-risk baby & 19 & 7.5 \\
Bleeding during labor & 16 & 5.7 \\
Macrosomia & 14 & 4.8 \\
Tubal ligation & 10 & 4.2 \\
Umbilical cord deformity & 10 & 3 \\
Maternal fit & 7 & 3 \\
Sudden hypertension & 3 & 2.1 \\
Multiple pregnancy & 1 & 0.9 \\
Previous uterine rupture & 3 & 0.3 \\
\hline
\end{tabular}

\section{DISCUSSION}

A highly significant association was found between the ages of the patients, parity and PCS rates in the study. Indeed, older females ( $\geq 30$ y) with higher parity $\geq$ 5) tended to have a lower rate of primary PCS as compared with younger $(<30 \mathrm{y})$ females with lower parity $(<5)$. This agree the findings in the study done by Khashoggi and his colleagues in 1995 [14]. The findings in this study can be explained on the basis of increased pregnancy complications in these younger females as compared with older females. These include cephalopelvic disproportion, pregnancy-induced hypertension and fetal distress. The other possible explanation can be that the population in this study may be younger. In addition to the role of social media and its availability in this age with wrong ideas about delivery.

Majority of the study sample (49.7\%) was primigravida, while (40.6\%) of frequency was multigravida, whereas the other rate is distributed to 
$9.7 \%$ of frequency was grand multigravida. I think this rate in primigravida may be because of fear women from labor pain, trauma or injury may occur to birth or maybe they have no family support during labor and birth. This finding was also reported by other studies $[14,15]$. But it different from this study [1] most women are multipara in comparison with $22 \%$ mothers how are primiparas.

Fetal distress is the common indications to the performance of PCS which present $22.1 \%$. That go with this study [16] and [4]. Despite its poor performance as a screening tool for fetal compromise delays in delivery for no reassuring fetal heart rate tracings remain the basis of many medico-legal actions in obstetrics. As a result, continuous electronic fetal monitoring has been observed to increase the rate of cesarean delivery compared with intermittent auscultation of the fetal heart rate during labor, and this increase occurs in both high-risk and low-risk patients but that wrong routine, because the fetal heart rate tracing undergoes periodic changes during labor. However, the use of cardiotocographic tracings (CTG) without the backing of other scientific methods may not be the proper manner of making a diagnosis of fetal distress. Alternatively, maybe missing in the reporting of CTG.

Prolonged labor was the second reason of PCS to occur intrapartum in our study (18.5\%) may be due to no good use of partogram in labor. An absolute indication for cesarean delivery this result go with this study [10] intensely.

Then malpresentation (mostly breech) was the third indications to perform PCS, which found $17.3 \%$. This agrees with this study [17]. While other study [14] consider that breech presentation was topped the list of indications. These conditions persist to labor time due to declines in training and experience of labour room staff.

Amniotic fluid leakage also had high percent among indications $16.4 \%$; I think this increasing belonged to recurrent urinary tract infection, genital tract infection, and high suspicion of chorioamnitis due to premature rupture of membrane, which go with decrease level of respecting the management by antibiotics among women, made the doctor to performance CS.

Cephalo-pelvic disproportion was $14.2 \%$. CPD could result from pelvic contraction due to macrosomia or subluxation of the pelvic bones, which found in multiparous females. It could also be a result of malpresentation, especially breech. That disagrees with this study $[14,10]$, which indicates CPD topped the list of indications The above five indications are considered as most common for performing a primary Cesarean section in our study and accounted for $88.5 \%$ of all sample. This result is in agreement with this study [1], stating these indications are responsible for $\% 85$ of all Cesarean deliveries in the USA.

In $43.6 \%$ of women, caesarean section was done when they were in labor (emergency). While (34.8\%) that elective caesarean section might be due to present of relative causes. But mother request had $(21.5 \%)$, the commonest reasons for maternal demand of caesarean section are fear of labor pains and complications in labor, suggesting suboptimal obstetric care. This finding go with the following studies $[1,15,4]$ Most women based their opinions on the experiences of other women who had experienced vaginal birth and the media due to insufficient and inadequate antenatal education.

\section{CONCLUSION}

Largest number of participant were primigravidarum, which read big and serious problems for women life in future. Most women had taken regular antenatal care. Fetal distress and prolonged labor were the most common indications for caesarean section. The fetal outcome was good that reflect good antenatal care and perinatal care.

\section{AUTHORS CONTRIBUTIONS}

All the authors have contributed equally.

\section{CONFLICT OF INTERESTS}

There is no possible conflict of interest related to this article was reported.

\section{REFERENCES}

1. Majeed AG. The study of indications and factors affecting the performance of caesarean section. Tikrit Med J 2010;2:145-50.

2. Saha L, Chowdhury SB. Study on the primary cesarean section. Mymensingh Med J. 2011;20:292-7.

3. Okonkwo NS, Ojengbede OA, Morhason Bello IO, Adedokun BO. Maternal demand for cesarean section: perception and willingness to request by Nigerian antenatal clients. Int J Women's Health 2012;4:141.

4. Sri AS, Kekhashan A. Institutional study of primary caesarean section among multigravida. Emergency 2016;184:80.

5. Chaillet N, Dumont A. Evidencebased strategies for reducing cesarean section rates: a meta-analysis. Birth 2007;34:53-64.

6. Betran AP, Torloni MR, Zhang J, Ye J, Mikolajczyk R, Deneux Tharaux $\mathrm{C}$, et al. What is the optimal rate of caesarean section at the population level? A systematic review of ecologic studies. Reproductive Health 2015;12:57.

7. Silver RM. Implications of the first cesarean: perinatal and future reproductive health and subsequent cesareans, placentation issues, uterine rupture risk, morbidity, and mortality. Seminars Perinatol 2012;36:315-23.

8. Ojiyi E, Dike E, Idrissa A. Primary caeserean section in grandmultiparae at mater misericordiae hospital afikpo: a $5 \mathrm{y}$ retrospective study. Nigerian J Clin Practice 2008;11:368-71.

9. Branch DW, Silver RM. Managing the primary cesarean delivery rate. Clin Obstet Gynecol 2012;55:946-60.

10. Tita ATN. When is primary cesarean appropriate: maternal and obstetrical indications. Seminars Perinatol 2012;36:324-7.

11. Fantini MP, Stivanello E, Frammartino B, Barone AP, Fusco D, Dallolio L, et al. Risk adjustment for inter-hospital comparison of primary cesarean section rates: need, validity and parsimony. BMC Health Serv Res 2006;6:100.

12. Metz TD, Allshouse AA, Gilbert SAB, Doyle R, Tong A, Carey JC. Variation in primary cesarean delivery rates by an individual physician within a single-hospital laborist model. Am J Obstetrics Gynecol 2016;214:531. e1-. e6.

13. Ministry of health/Environment. Annual Statistical Repot; 2016.

14. Khashoggi T, Soltan MH, Al Nuaim L, Addar M, Chowdhury N, Adelusi B. Primary cesarean section in King Khalid University hospital: indications and obstetric outcome. Ann Saudi Med 1995;15:585-8.

15. Faisal I, Matinnia N, Hejar AR, Khodakarami Z. Why do primigravidae request caesarean section in a normal pregnancy? A Qualitative Study Iran Midwifery 2014;30:22733.

16. Simpson LL. When is primary cesarean appropriate: fetal indications. Seminars Perinatol 2012;36:328-35.

17. Caughey AB, Cahill AG, Guise JM, Rouse DJ. Safe prevention of the primary cesarean delivery. Am J Obstetrics Gynecol 2014;210:179-93. 